\title{
Mental health in The Netherlands
}

\section{R. J. A. ten Doesschate ${ }^{1}$ and P. P. G. Hodiamont ${ }^{2}$}

1Psychiatrist, Adhesie, Deventer, The Netherlands, email r.tendoesschate@adhesie.nl ${ }^{2}$ Psychiatrist, Tilburg University, The Netherlands, email p.p.g.hodiamont@uvt.nl

b he Netherlands borders the North Sea and is located between Belgium and Germany. Its total area is about $41500 \mathrm{~km}^{2}$, nearly $34000 \mathrm{~km}^{2}$ of which is land area. The country consists mostly of coastal lowland and land reclaimed from the sea (polders). An extensive system of dykes and dams protects nearly one-half of the total area from being flooded.

The Netherlands is one of the most densely populated countries in the world, at around 480 persons per $\mathrm{km}^{2}$ of land area (total population of 16299000 as of 1 January 2005). About $20 \%$ of the population have a foreign background. Of the total number of jobs available, about one-sixth are in trade, one-sixth in industry, one-eighth in business and one-eighth in health and social care. Agriculture and fisheries account for only $1.5 \%$ of the workforce, so it is fair to call The Netherlands an advanced post-industrial society (Metz \& Poorter, 1998).

According to the Healthcare Budgetary Framework (Ministry of Health, Welfare and Sport), the cost of healthcare was $€ 45$ billion in 2004, representing $9.2 \%$ of gross domestic product (GDP). Healthcare expenditure as a percentage of GDP in The Netherlands is on a level with the middle group of European countries.

The annual prevalence rate of mental conditions (excluding alcohol and substance misuse) in the Dutch population is $16 \%$. Over $40 \%$ of the Dutch population have at one time had a mental condition (including alcohol and substance misuse). In the period 2000-4 one in every three Dutch adults with a mental condition sought help.

\section{Mental health policy}

Mental healthcare is part of the portfolio of the Minister of Health. Since the late 1990s, government policy has been based on principles such as continuity of care. Collaboration between clinical and ambulatory care resulted in the establishment of integrated institutes for mental healthcare.

Mental healthcare is mainly financed through the Exceptional Health Expenses Act (Algemene Wet Bijzondere Ziektekosten, AWBZ), but this mechanism is due to change over the next few years. A substantial part of mental healthcare will be transferred to the health insurance system and be financed in a manner similar to physical healthcare. Payments will be based on 'diagnosis treatment combinations' (diagnose behandel combinaties, DBCs). Only hospitalisation exceeding 12 months will be paid through the Exceptional Health Expenses Act.

Government policy on mental healthcare is also changing. Mental healthcare is now integrated into general healthcare.
The introduction of evidence-based programmes and guidelines will improve the diagnosis and treatment of psychiatric disorders, both in primary care and in specialist care; a system of 'stepped care' will also be introduced. Competition between care providers will be promoted and new mental healthcare organisations are being persuaded to enter the (mental) health market. The purpose of this competition is to keep costs down and to improve the quality of care.

\section{Mental health service delivery}

Mental healthcare is delivered by some 40 integrated institutions (hospital, day hospital, out-patient and community care) for children, adults and elderly people, of which ten are for children and adolescents, nine for people with addictions and seven for forensic psychiatric care. The total number of beds is 29000 . Mental healthcare uses $8 \%$ of the total healthcare budget of $€ 45$ billion and employs about 40000 people.

\section{Psychiatric training}

Undergraduate medical training takes 6 years and ends with the final licensing examination, after which the student obtains the formal qualification to practise medicine. Nearly all graduates continue their studies with specialty training. Dutch specialist training is elaborately regulated and closely monitored; there is no final examination. Regulations for specialist training specify the requirements for the specialists in charge of the training, the teaching institutions and the duration, content and conditions of training.

Candidates for training in psychiatry apply for a place on an acknowledged specialist training programme. If accepted by the trainer, they are required to notify the Committee for the Registration of Medical Specialists (MSRC) and to submit a training schedule for approval. This schedule must accord with the regulations for psychiatry. The trainee works as a resident under the supervision of a specialist trainer within the framework of specific teaching rules. Residents are evaluated annually and feedback is sent to the MSRC. In case of concerns about the resident's progress, the MSRC is empowered to prolong, or even terminate, the training. Once the resident has completed training, the MSRC may, on receipt of the trainer's final statement, enter them as a psychiatrist on the Dutch register of specialists. The resident must provide the MSRC with detailed information on the training, in the form of a logbook. As one of the requirements for registration, doctors must publish a paper in a peer-reviewed journal or present a lecture at a peer-reviewed scientific meeting. 
In 2006, 664 (266 male, 398 female) doctors were trained to become psychiatrists. The 2616 (1649 male, 967 female) registered psychiatrists constitute around $15 \%$ of the total number of medical specialists in The Netherlands (17030).

Training for psychiatrists in The Netherlands complies with most requirements of the Board of Psychiatry of the Union Européenne des Médecins Spécialistes (UEMS; see http:// www.uemspsychiatry.org/board/reports/Chapter6-11.10.03. pdf). The only departure from this guidance provided by the UEMS is in the duration of training, which in The Netherlands is 4.5 years instead of the recommended 5 .

Training in community psychiatry and psychotherapy is an integral part of the programme. Also, 50 sessions of psychotherapy undergone by the trainee (i.e. as a client) is a mandatory part of training.

Most training in psychiatry is carried out in the integrated mental health institutes (27 of these offer training), but it is also done in seven of the university clinics and in one psychiatric department at a general hospital.

Assessment visits to every training scheme are mandatory at least every 5 years. The assessment team includes a trainee who speaks independently to the trainees on that scheme.

There are no formal sub-specialties in psychiatry in The Netherlands, although there is a register of child and adolescent psychiatrists.

\section{Re-registration}

Every medical specialist has to be re-registered every 5 years. To meet the revalidation criteria, psychiatrists are required to work at least 16 hours a week in psychiatry for 5 years and to accumulate 40 hours of continuing medical education (CME) a year. In addition, psychiatrists should take part every 5 years in the assessment visit scheme of the Dutch Psychiatric Association (Nederlandse Vereniging voor Psychiatrie, NVvP).

\section{Allied professions}

All healthcare professionals providing direct patient care must, by law, be registered under the Individual Healthcare Professions Act - that is, on the wet Beroepen Individuele Gezondheidszorg (BIG) register. The legislation covers both general medical doctors and specialists.

An estimated 16000 nurses work in mental healthcare, $30 \%$ of whom are graduates and $2 \%$ of whom have achieved a professional qualification at a masters or specialist level. About 5500 generalist psychologists and an estimated 1100 specialist psychologists (clinical psychologists, klinisch psycholoog) work in mental healthcare. As in psychiatry, psychotherapy is an integral part of the professional training of specialist psychologists. Furthermore, there are about 1400 psychotherapists and an estimated 600 medical doctors working in mental healthcare.

\section{Main areas of research}

Research in psychiatry in The Netherlands is concentrated around the seven university clinics, although the efforts of the integrated mental health institutes are growing. An important impetus to mental health research in general has been given by the ZonMw (the national health council appointed by the Ministry of Health; http://www.zonmw. $\mathrm{nl} /$ programmas/geestkracht) and The Netherlands Organisation for Scientific Research (NOW) to promote quality and innovation in the field of health research and care. An ambitious long-term programme, with a budget of $€ 24$ billion, under the name 'Geestkracht' (Mental Power), has three specific objectives:

o to promote application-oriented research, knowledge transfer and implementation

O to facilitate $\mathrm{PhD}$ research and to promote the availability and uptake of adequate educational opportunities for mental health researchers

$O$ to strengthen research and knowledge infrastructure through cooperation between different scientific institutes and institutions providing healthcare.

GROUP (http://www.groupproject.nl) is a national consortium of 39 university and non-university institutes that concentrates its research on psychotic disorders. 'Generation $\mathrm{R}$ and Trails' and NESDA (Netherlands Study on Depression and Anxiety, http://www.nesda.nl) are both engaged in research concerning children and young adults, and anxiety and depression respectively.

\section{Human rights issues}

Although there are no exact data available, the general view is that seclusion rooms are used more frequently in The Netherlands than in neighbouring countries. One of the reasons for this is that treatment against the patient's will is restricted by law. Only when there is acute danger to the patient or others is carefully monitored forced medication allowed. Fortunately, the growing feeling of discomfort among professionals, psychiatrists and nurses is slowly contributing to the re-evaluation of the use of seclusion rooms. Furthermore, there are initiatives to change mental health legislation in The Netherlands which would lead to (involuntary) treatment being sometimes used as an alternative to seclusion and restraint.

\section{Challenges}

Further implementation of multidisciplinary guidelines is one of the challenges for the healthcare professions. Psychiatrists, supported by their scientific association, will play an important part in this implementation process.

Although prevention is not neglected at the moment, primary and secondary prevention, in cooperation with public healthcare, should receive more emphasis in the near future.

As mentioned above, a reduction in the use of restraint, supported by scientific research, will be one of the major challenges for psychiatrists in the coming decade.

It is not unlikely that psychiatric patients with chronic illness will fall victim to greater competition in the healthcare market. It is reasonable to expect that the attention of the insurance companies, healthcare organisations and professionals will be focused on the less complicated cases 
(typically patients with Axis I disorders). The challenge for psychiatrists and other professions will be to ensure that patients with chronic illness receive adequate (community) mental healthcare in the future.

\section{Reference}

Metz, J.\& Poorter, J. (1998) The Netherlands. In Medicine and Medical Education in Europe (ed. G. Eysenbach). Thieme.

\title{
The teaching and training of psychiatry in Thailand
}

\author{
Pichet Udomratn, MD FRCPsychT
}

Department of Psychiatry, Faculty of Medicine, Prince of Songkla University, Hat Yai, Songkhla 90110, Thailand, email upichet@medicine.psu.ac.th

\begin{abstract}
$\mathrm{n}$ Thailand, we have only two programmes for residency training in psychiatry: one is general or adult psychiatry, which takes 3 years to complete; the other is child and adolescent psychiatry, which takes 4 years. There are nine institutes that offer residency training but only three medical schools have the capacity to offer training in both general and child psychiatry (Table 1).

The curriculum for training in adult psychiatry is similar to that in many other Asian countries. It is outlined in Table 2. Most residents learn psychiatry in both in- and out-patient settings simultaneously, although some institutes prefer to have their trainees initially learn in a psychiatric ward, during their first 3-6 months of training.

It is compulsory that all accredited training institutes arrange at least 2 hours of supervision per week. Trainees will meet one or two supervisors during the 3-month rotation. Most of them will have one supervisor who is in charge of the ward staff and another who supervises care of out-patients. The second- and third-year residents will have an extra supervisor specifically to supervise psychotherapy cases.
\end{abstract}

\section{Outline of the curriculum}

Most institutes emphasise interviewing techniques and mental status examination during the first 3 months. The techniques are taught through lectures and observation. Thereafter they are practised throughout the programme, both individually with feedback by supervisors and in group sessions - 'interviewing seminars' - with feedback from peers and staff.

Trainees learn the concepts of psychological treatment largely from lectures, but also in book clubs and topic discussion sessions.

They have to manage at least two psychotherapy cases during the 3 years of training, including one of short-term therapy and another of long-term treatment. They normally review cases with their supervisor once a week and bring cases for discussion in a psychotherapy seminar once a month. Apart from psychotherapy, trainees must also study another psychological treatment method, such as behaviour therapy, cognitive therapy or family therapy. They are not required to practise these methods, however, as there are too few skilled and certified therapists in those areas to supervise them.

For electroconvulsive therapy (ECT), trainees will listen to a lecture first. Then they will observe staff and/or senior

Table 1 Institutes that provide psychiatric residency training in Thailand

\begin{tabular}{|c|c|c|c|}
\hline Medical school/institute & Province & $\begin{array}{l}\text { General } \\
\text { psychiatry }\end{array}$ & $\begin{array}{l}\text { Child } \\
\text { psychiatry }\end{array}$ \\
\hline Siriraj Medical School & Bangkok & Yes & Yes \\
\hline Ramathibodi Medical School & Bangkok & Yes & Yes \\
\hline Phramongkutklao Hospital & Bangkok & Yes & No \\
\hline $\begin{array}{l}\text { Chulalongkorn Medical } \\
\text { School }\end{array}$ & Bangkok & Yes & Yes \\
\hline Chiang Mai Medical School & Chiang Mai & Yes & No \\
\hline $\begin{array}{l}\text { Prince of Songkla Medical } \\
\text { School }\end{array}$ & Songkhla & Yes & No \\
\hline Khon Kaen Medical School & Khon Kaen & Yes & No \\
\hline $\begin{array}{l}\text { Somdet Choapraya Institute } \\
\text { of Psychiatry }\end{array}$ & Bangkok & Yes & No \\
\hline $\begin{array}{l}\text { Yuwaprasart } \\
\text { Waithayopathum } \\
\text { Psychiatric Hospital }\end{array}$ & Samut Prakan & No & Yes \\
\hline
\end{tabular}

Table 2 General psychiatry curriculum in Thailand

\begin{tabular}{|lll} 
Year of training & Topic & Duration \\
First year & $\begin{array}{l}\text { General adult psychiatry } \\
\text { Mental health hospital psychiatry }\end{array}$ & 6 months \\
& Neurology & 3 months \\
Second year & $\begin{array}{l}\text { General adult psychiatry } \\
\text { Child and adolescent psychiatry }\end{array}$ & 6 months \\
& Consultation-liaison psychiatry & 3 months \\
Third year & $\begin{array}{l}\text { General adult psychiatry } \\
\text { Addiction psychiatry }\end{array}$ & 6 months \\
& $\begin{array}{l}\text { Community psychiatry } \\
\text { Forensic psychiatry }\end{array}$ & 1 months \\
& $\begin{array}{l}\text { Day hospital, juvenile court } \\
\text { Electives }\end{array}$ & 0.5 months \\
& & 3 months
\end{tabular}

